\title{
Exogenous application of Nitric Oxide donors Regulates Short- term Flooding Stress in Soybean
}

\author{
Muhammad Aaqil Khan ${ }^{1}$, Abdul Latif Khan ${ }^{2}$, Qari Muhammad Imran ${ }^{1}$, Sajjad Asaf ${ }^{2}$, Sang Uk Lee ${ }^{1}$, Byung-Wook \\ Yun $^{1}$, Muhammad Hamayun ${ }^{3}$, Tae-Han Kim ${ }^{4}$, In-Jung Lee ${ }^{\text {Corresp. } 1}$ \\ ${ }^{1}$ Applied biosciences, Kyungpook National University, Degue, South Korea \\ 2 Chair of Oman's Medicinal Plants \& Marine Natural Product, University of Nizwa, Nizwa, Oman \\ 3 Department of Botany, Abdul Wali Khan University, Mardan, Pakistan \\ 4 School of agricultural civil \& bio-industrial machinery engineering, Kyungpook National University, Daegu, South Korea \\ Corresponding Author: In-Jung Lee \\ Email address: ijlee@knu.ac.kr
}

Short-term water submergence to soybean (Glycine max L.) create hypoxic conditions hindering plant growth and productivity. Nitric oxide (NO) is considered a stress-signalling and stress-evading molecule, however, little is known about its role during flooding stress. We elucidated the role of sodium nitroprusside (SNP) and S-nitroso L-cysteine (CySNO) as NO donor in modulation of flooding stress-related bio-chemicals and genetic determinants of associated nitrosative stress to Daewon and Pungsannamul soybean cultivars after $3 \mathrm{~h}$ and $6 \mathrm{~h}$ of flooding stress. The results showed that exogenous SNP and CysNO induced glutathione activity and reduced the resulting superoxide anion contents during short-term flooding in Pungsannamul soybean. The exo- SNP and CysNO triggered the endogenous Snitrosothiols, and resulted in elevated abscisic acid ( $A B A)$ contents in both soybean cultivars overtime. To know the role of $A B A$ and NO related genes in short-term flooding stress, the mRNA expression of S-nitrosoglutathione reductase (GSNOR1), NO overproducer1 (NOX) and nitrate reductase (NR), Timing of CAB expression1 (TOC1), and $A B A$-receptor ( $A B A R$ ) were assessed. The transcripts accumulation of GSNOR1, NOX1, and $N R$ being responsible for NO homeostasis, were significantly high in response to early or later phases of flooding stress. ABAR and TOC1 showed a decrease in transcript accumulation in both soybean plants treated with exogenous SNP and CySNO. The exoSNP and CySNO could impinge a variety of biochemical and transcriptional programs that can mitigate the negative effects of short-term flooding stress in soybean. 
1 Exogenous application of Nitric Oxide donors Regulates Short-term Flooding Stress in

3 Muhammad Aaqil Khan ${ }^{1}$, Abdul Latif Khan ${ }^{2}$, Qari Muhammad Imran ${ }^{1}$, Sajjad Asaf ${ }^{2}$, Sang Uk

4 Lee $^{1}$, Byung-Wook Yun ${ }^{1}$, Muhammad Hamayun ${ }^{3}$, Tae Han Kim ${ }^{4}$, In-Jung Lee ${ }^{1 *}$

5

${ }^{1}$ Applied Biosciences, Kyungpook National University, Daegu, South Korea

${ }^{2}$ Chair of Oman's Medicinal Plants \& Marine Natural Product, University of Nizwa, Nizwa,

7

Oman

8

${ }^{3}$ Department of Botany Abdul Wali Khan University Mardan, Pakistan

${ }^{4}$ School of agricultural civil \& bio-industrial machinery engineering, Kyungpook National

University, Daegu, South Korea

11

12

13

14

15

16

17

18

19

20

21 Correspondence; Prof. In-Jung Lee, E-mail; ijlee@,knu.ac.kr

22

Peer] reviewing PDF | (2018:12:33773:2:1:NEW 5 Aug 2019) 
23 Abstract

24 Short-term water submergence to soybean (Glycine max L.) create hypoxic conditions hindering 25 plant growth and productivity. Nitric oxide (NO) is considered a stress-signalling and stress26 evading molecule, however, little is known about its role during flooding stress. We elucidated the 27 role of sodium nitroprusside (SNP) and S-nitroso L-cysteine (CySNO) as NO donor in modulation of flooding stress-related bio-chemicals and genetic determinants of associated nitrosative stress to Daewon and Pungsannamul soybean cultivars after $3 \mathrm{~h}$ and $6 \mathrm{~h}$ of flooding stress. The results showed that exogenous SNP and CysNO induced glutathione activity and reduced the resulting superoxide anion contents during short-term flooding in Pungsannamul soybean. The exo- SNP and CysNO triggered the endogenous $S$-nitrosothiols, and resulted in elevated abscisic acid (ABA) contents in both soybean cultivars overtime. To know the role of ABA and NO related genes in short-term flooding stress, the mRNA expression of $S$-nitrosoglutathione reductase (GSNORI), NO overproducerl (NOX) and nitrate reductase (NR), Timing of CAB expression1 (TOC1), and $A B A$-receptor $(A B A R)$ were assessed. The transcripts accumulation of GSNOR1, NOX1, and NR being responsible for NO homeostasis, were significantly high in response to early or later phases of flooding stress. $A B A R$ and $T O C 1$ showed a decrease in transcript accumulation in both soybean plants treated with exogenous SNP and CySNO. The exo- SNP and CySNO could impinge a variety of biochemical and transcriptional programs that can mitigate the negative effects of shortterm flooding stress in soybean. 


\section{Introduction}

Flooding is an abiotic stress which adversely affects the growth and productivity of different plant species all over the world (Jackson \& Colmer (2005). It is estimated that global warming might impact $70 \%$ of the world population associated with agriculture, and that the losses incurred through floods will increase up to five folds (Alfieri et al. 2016). Flooding results in number of crises including slow gas exchange and low light levels under water which are responsible for both carbon and energy deficit leading to plant death (Sasidharan et al. 2018). Submergence also changes the redox status of the cell and reports suggested that flooding may alter the concentrations of oxygen-derived free radicals such as reactive oxygen species (ROS), and nitric oxide (NO), (Bailey-Serres \& Voesenek 2008). Flooding stress is fatal to all higher plants including crops, however, the impact will be much higher in crops sensitive to flooding stress. One of the most sensitive crop to flooding is the economically important soybean, as millions of tons of soybean are lost due to flooding in different regions of South America (BaileySerres et al. 2012). There is an estimated 25\% reduction in soybean yield due to flood injuries in North America, Asia and other regions of the world where soybean is rotated with rice in paddy fields (Mustafa \& Komatsu 2014; Tewari \& Arora 2016). Flooding stress adversely affects the growth and productivity of soybean with an approximate $17 \%-43 \%$ reduction at the vegetative stage while 50\%-56\% at the reproductive stage (Mustafa \& Komatsu 2014; Visser \& Pierik 2007).

Flooding stress generates hypoxic conditions which lead to the unavailability of molecular oxygen to the non-photosynthetic tissues of the plants. The prolonged submergence results in the manifestation of stress ethylene, whereas, the excessive amount of ethylene inhibits root elongation and ultimately cause plant death (Visser \& Pierik 2007), which is often removed by the aerenchyma; however, this depends on the level, intensity, and duration of flooding stress. 
Additionally, this further signals a plethora of physiological networks associated with plant growth and flooding stress. It involves activating different endogenous phytohormones (abscisic acidABA, gibberellins-GA, and auxin) and antioxidant enzymes (peroxidase, and catalases). Abscisic acid (ABA) have been reported for its potential role in flooding stress conditions and also known as stress phytohormone because of its response and distinct role in plant adaptation during abiotic stresses. Endogenous ABA levels increase rapidly, activating specific signaling pathways and modifying gene expression levels in response to abiotic stress (O'Brien \& Benkova 2013).

Several studies have been reported changes in ABA concentrations in different plants, including alfalfa (Castonguay et al. 1993), tobacco (Hurng et al. 1994), pea (Jackson et al. 1988), tomato (Else et al. 1995), gerbera daisy (Olivella et al. 2000); Citrus (Arbona \& Gómez-Cadenas 2008; Rodriguez-Gamir et al. 2011); and apple (Bai et al. 2011) under flooding stress. The ABA response to flooding may differ and depend on the plant species and duration of flooding. Other studies reported that flooding stress have associated ABA accumulation with an increase in reactive oxygen species (ROS), in root parts of Glycine max L (Vantoai \& Bolles 1991), and Triticum aestivum L. (Biemelt et al. 2000) and leaf part of Zea mays L. (Yan et al. 1996). A timecourse study in Arabidopsis thaliana L. showed that ABA increased with flooding stress, triggering stomatal closure and changes in hydrogen peroxide $\left(\mathrm{H}_{2} \mathrm{O}_{2}\right)$ followed by an increase in antioxidant enzyme activities (Liu et al. 2012). The role of ABA is pivotally important in transcriptional regulation of protein-encoding genes and has been estimated up to $10 \%$ (Nemhauser et al. 2006).

Plants respond to environmental stresses through complex mechanisms involving regulatory genes that mediate signal transduction during stress. These unfavorable conditions results in the production of important molecules called reactive nitrogen intermediates (RNIs) 
89 (Burniston \& Wilson), which regulate multiple physiological and biochemical processes in plants

90 (Durzan \& Pedroso 2002; Valderrama et al. 2007). The primary source of production of these RNIs

91 is NO, which has gained significant attention during the last couple of decades (Delledonne et al.

92 1998; Durner et al. 1998; Yun et al. 2011). After its recognition as a signaling molecule, NO has

93 been reported to play a key role in plant resistance against abiotic and biotic stressors (Yu et al.

94 2014a; Yun et al. 2011). The production of NO and the mechanism of its action have been well

95 elucidated in animals (Alderton et al. 2001) but remain unclear in plants. There are two major

96 pathways for NO biosynthesis reported in plants to date: the oxidative route involving NO

97 synthesis from L-arginine ( $\mathrm{L}-\mathrm{Arg}$ ) polyamines or hydroxyl amines, and the reductive route

98 involving nitrate reductase (NR) enzyme (Yu et al. 2014a).

Reactive nitrogen species (RNS), the NO) derived molecules are relatively less known redox-active molecules that like ROS are produced after stress perception. The most studied among them is the group of S-nitrosothiols (SNOs) that is formed by the interaction of NO with intracellular sulfhydryl-containing molecules and are of great interest as they are more stable in solution than is NO. Therefore, they help in intracellular signaling, storage, and delivery of NO (Leterrier et al. 2011). One of the important SNOs is S-nitrosoglutathione (GSNO) which is formed by the S-nitrosylation reaction of $\mathrm{NO}$ with glutathione (GSH) and is NO mobile reservoir thereby having a strong impact on cellular redox status (Shahzad et al. 2016). GSNO reductase (GSNOR) is an enzyme that catalyses the NADH-dependent reduction of GSNO to GSSG and NH3 (Jensen et al. 1998). Therefore, GSNOR activity can regulate cellular NO homeostasis (Leterrier et al. 2011). NOX1 (nitrous oxide overexpressor 1) also reportedly involved in NO metabolism (Wang et al. 2017a). Mutation in the gene resulted in increased accumulation of NO resulting in reduced 111 root growth phenotype (Wang et al. 2017a). This suggests that $N O X 1$ positively regulates NO 
112 homeostasis. In addition, transcriptomic analysis has made it easy to show the global changes in 113 gene expression in response to a particular stimulus. A number of potential candidate genes have

114 been reported to regulate various biological processes in Arabidopsis by Hussain et al. (2016) and 115 in Trifolium repens by Zhang et al. (2018). However, detail investigation involving in vitro 116 analyses are required to validate particular gene's function. There are other reports that described 117 the negative role of NO through N-end rule pathway (i) Ac/N-end rule pathway, (ii) Arg/N-end 118 rule pathway or phytoglobine. When plants were subjected to flooding stress like ethylene the 119 concentration of NO also increase due to the restriction of gas diffusion. However, NO is highly 120 reactive and react with oxygen to produce nitrite and $\mathrm{NO}_{3}$ or with $\mathrm{ROS}$ to form additional reactive nitrogen species (Delledonne et al., 2001; Chamizo-Ampudia et al., 2017). In addition, (Magalhaes

122 et al. 2000) and (Manac'h-Little et al. 2005) reported that exo-NO application increases ethylene 123 production in various plant species, possibly via enhanced ACO activity. NO role under hypoxic 124 condition has also been described. Reports suggested that ERFVIIs are important transcriptional 125 regulators of hypoxia responses of hypoxia adaptive gene expression (Gasch et al. 2016; Gibbs et al. 2011; Hinz et al. 2010; Licausi et al. 2011). Studies have revealed that the presence of a characteristic N-terminal motif makes ERFVIIs direct targets of the N-end rule pathway of proteolysis, where, in the presence of both ambient NO and oxygen, these proteins are ubiquitinated and degraded in Arabidopsis (Gibbs et al. 2011; Gibbs et al. 2014; Licausi et al. 2011). When either the NO or oxygen concentration declines, ERFVIIs are no longer flagged for ubiquitination, accumulate, and activate downstream target genes. 
135 soybean plants subjected to flooding stress has been largely ignored in previous studies. NO has a

136 well-established role in the key physiological processes relating to plant development and

137 immunity (Neill et al. 2008; Yu et al. 2014b; Yun et al. 2016). Its reactivity is also of crucial

138 importance for its signaling functions, as NO is a highly reactive and toxic radical endogenously

139 produced by plants in response to a variety of stressors (Wang et al. 2013). Additionally, NO plays

140 a central role in plant growth and development (Shi et al. 2007; Talukdar 2013; Wang et al. 2017b).

141 Studies have shown that exogenous NO application mitigates the stress induced by salinity (Shi et

142 al. 2007), high or low temperatures (Hasanuzzaman et al. 2012), heavy metals (Talukdar 2013;

143 Wang et al. 2017b), drought (Jday et al. 2016), and toxic chemicals (Asgher et al. 2016; Khan et

144 al. 2017) in various crop plants. Vladkova et al., (2010) and Alderton et al., (2001) reported that

145 SNP donated NO stimulates overall photosystem II electron transport rate.

Some recent studies have elucidated that exogenous NO application alleviates flooding stress. These studies demonstrated that the application of NO helps in plant fitness against hypoxia and waterlogging (Dordas 2015; Fan et al. 2017; Gupta et al. 2016). The regulatory role of NO in biotic and abiotic stress conditions have been reviewed in detail (Misra et al. 2011). However, the effects of NO in regulating endogenous phytohormones and the implications of NO-induced redox imbalance in mitigating flooding stress have not been investigated fully. In the present study, we aimed to understand the interactive role of exogenous SNP and CySNO as NO donor at phytohormonal and molecular level of the plant under short-term flooding stress. Hence, a $3 \mathrm{~h}$ and

$1546 \mathrm{~h}$ flooding stress was given to soybean plants (Daewon; normal and Pungsannamul; sensitive) and the exogenous NO was applied to see the regulation of oxidative stress (superoxide anion,

156 reduce glutathione), phytohormone (abscisic acid), molecular transcript (NOX1, GSNOR1, NR, $157 A B A R$, and $T O C 1$ ) and total $S$-nitrosothiol during stress conditions. Furthermore, we studied the 
158 molecular characterization of $\mathrm{NO}$ and $\mathrm{ABA}$ related transcripts of potent genes in both soybean

159 cultivars under short term flooding stress.

160

161

162

163

164

165

166

167

168

169

170

171

172

173

174

175

176

177

178

179

\section{Materials and Methods}

\subsection{Plant growth, flooding stress and exogenous NO application}

Soybean seeds (Glycine max L.) of two varieties (Daewon; normal and Pungsannamul; sensitive) were collected from Kyungpook National University's Genetic Resource Centre, Republic of Korea. The seeds were surface sterilized using sodium hypochlorite (2.5\%) solution for 20 mint on a shaker at $120 \mathrm{rpm}$ and washed twice in distilled water. The seeds were then subjected to a germination assay in plastic trays under greenhouse conditions with day/night cycle of $14 \mathrm{~h}$ at $28^{\circ} \mathrm{C} / 10 \mathrm{~h}$ at $25^{\circ} \mathrm{C}$ and relative humidity of $60 \%-70 \%$ with natural light exposure. Uniform seedlings were selected randomly at leaf stage 1 (VI) and nine plants were planted in each plastic tray $(41 \mathrm{~cm} \times 24.5 \mathrm{~cm})$ containing nutrient-rich soil (peat moss $(10 \%-15 \%)$, perlite $(35 \%-$ $40 \%$ ), coco peat $(45 \%-50 \%)$, zeolite $(6 \%-8 \%), \mathrm{NH}_{4}^{+} \sim 0.09 \mathrm{mg} \bullet \mathrm{g}^{-1}, \mathrm{NO}_{3}^{-} \sim 0.205 \mathrm{mg} \bullet \mathrm{g}^{-1}$, $\mathrm{P}_{2} \mathrm{O}_{5} \sim 0.35 \mathrm{mg} \bullet \mathrm{g}^{-1}$, and $\left.\mathrm{K}_{2} \mathrm{O} \sim 0.1 \mathrm{mg} \bullet \mathrm{g}^{-1}\right)$. This makes a total of 45 plants for each treatment structure.

When the plants reached vegetative leaf stage 3 (V3), flooding stress was applied to maintain the water level up to $7 \mathrm{~cm}$ above the soil surface (Partial submergence). The experimental design (randomized block design) consisted of a control in which soybeans did not receive any treatment (Cont.), soybean plants subjected to flood stress only (CF), flood stress in addition to the application of $250 \mu \mathrm{M}$ SNP (from stock solution of $100 \mathrm{mM}$ SNP take $2.5 \mathrm{ml} / \mathrm{L}$ to make final concentration of $250 \mu \mathrm{M} \mathrm{SNP}$ ), and flooding stress in addition to the application of exogenous 250 
180

181

182

183

184

185

186

187

188

189

190

191

192

193

194

195

196

197

198

199

200

201

202

87

$\mu \mathrm{M}$ CySNO (from stock solution of $250 \mathrm{mM}$ CySNO take $1 \mathrm{ml} / \mathrm{L}$ to make final concentration of $250 \mu \mathrm{M})$. The amount of NO donor (SNP and CySNO) were pre-dissolved in distilled water and applied on soybean plants compared to control treatments. After 3 and $6 \mathrm{~h}$ of flooding stress the plants were harvested, frozen in liquid nitrogen and stored at $-70^{\circ} \mathrm{C}$ for further analyses. Each treatment was comprised of five pots, each pot containing nine plants. Thus making a total of 45 plants to assess the effect of individual treatment. The biochemical, genes expression and phytohormonal analysis were performed in triplicate.

\subsection{ROS generation and quantification}

For superoxide anion production analysis, the detailed method of (de Sousa et al. 2017; Doke 1983; Gajewska \& Skłodowska 2007) were followed by measuring the reduction of exogenously supplied nitroblue tetrazolium (NBT). $1 \mathrm{~g}$ of fresh shoot plant powder sample was immersed in 0.01M sodium phosphate buffer $(\mathrm{pH} 7.0)$ containing $0.05 \%(\mathrm{w} / \mathrm{v})$ NBT and $10 \mathrm{mM}$ sodium azide $\left(\mathrm{NaN}_{3}\right)$ and kept for $1 \mathrm{~h}$ at room temperature. Thereafter, $5 \mathrm{ml}$ of the solution was transferred into a new test tube and heated for $15 \mathrm{~min}$ at $85^{\circ} \mathrm{C}$ in a water bath. Immediately after heating, the solution was cooled down in ice and vacuum filtered. The absorbance of the sample was read at $580 \mathrm{~nm}$ on SHIMADZU spectrometer (Kyoto, Japan). Superoxide anion scavenging activity was calculated using the following equation: \% Scavenging $=\left(\mathrm{A}_{580}\right.$ Control $-\mathrm{A}_{580}$ Sample $/ \mathrm{A}_{580}$ Control) $\times 100$. The experiment was repeated in triplicate.

To determine the reduction in glutathione content was estimated using the detailed procedure described by (Asaf et al. 2017; Ellman 1959; Khan et al. 2017). In brief, each sample (500 mg) were powdered in a chilled mortar and pestle with liquid nitrogen and was treated with $3 \mathrm{ml}$ of $10 \%$ Trichloro Acetic Acid (TCA). The homogenate was centrifuged at $4{ }^{\circ} \mathrm{C}$ for $15 \mathrm{~min}$ at 
$20310,000 \times \mathrm{g}$. The resulting supernatant was then transferred into a new tube. One milliliter of the

204 supernatant was combined with $0.5 \mathrm{ml} \mu \mathrm{l}$ of 5.5-dithio-bis (2-nitrobenzoic acid)(75.3 $\mathrm{mg}$ in $30 \mathrm{ml}$

205 of $100 \mathrm{mM}$ phosphate buffer $\mathrm{pH} 6.8): 3 \mathrm{ml}$ of $150 \mathrm{mM}$ sodium phosphate buffer $\left(\mathrm{NaH}_{2} \mathrm{PO}_{4}, \mathrm{pH}\right.$

206 7.4) and were then incubated at $30^{\circ} \mathrm{C}$ for $5 \mathrm{~min}$. The absorbance of the solution was measured at

$207412 \mathrm{~nm}$ with the spectrophotometer (SHIMADZU, Kyoto, Japan) and the GSH content was

208 estimated using a standard curve. The experiment was repeated three time for each sample.

\subsection{Endogenous SNO quantification} tissue (shoot) was ground in liquid nitrogen to a fine powder using a mortar and pestle. The ground sample was then mixed with $1 \mathrm{ml}$ extraction buffer (1X PBS, $\mathrm{pH} 5.4$ ) and centrifuged at 13,000× $\mathrm{g}$ for $10 \mathrm{~min}$. The supernatant was transferred to a fresh tube and again centrifuged at $15,000 \times \mathrm{g}$

215 for $10 \mathrm{~min}$. Proteins were quantified using the Bradford assay according to the manufacturer's standard protocol. A standard curve was constructed to measure protein concentration by measuring optical density (OD) of bovine serum albumin (BSA) standards at $595 \mathrm{~nm}$ wavelength using spectrophotometer. For SNO determination, $100 \mu 1$ of the plant extracts were injected into the purge vessel of the NO Analyser (NOA 280i, Sievers USA) containing the reducing buffer protein) in each samples were calculated using standard curve plotted against the OD595 values

222 for each standard of CysNO. The standard curve was used to calculate total $S$-nitrosothiol levels 223 in each sample. 


\subsection{Endogenous ABA quantification}

At harvest, soybean plants (shoot) were immediately frozen in liquid nitrogen and ground 227 using a mortar and pestle. Endogenous ABA content was analysed following the modified protocol adopted from (Kamboj et al. 1999; Qi et al. 1998). The powdered samples were treated with $30 \mathrm{ml}$ of extraction solution containing 95\% isopropanol, 5\% glacial acetic acid, and $20 \mathrm{ng}$ of $[( \pm)-$ $\left.3,5,5,7,7,7-\mathrm{d}^{6}\right]-\mathrm{ABA}$. The extracts were dried and methylated by adding diazomethane for GC/MS-SIM (6890 N network GC system, and 5973 network mass-selective detector; Agilent Technologies, Palo Alto, CA, USA) analysis. For quantification, the Lab-Base (Thermo Quest, Manchester, UK) data system software was used to monitor responses to ions of $m / e 162$ and 190 for Me-ABA and 166 and 194 for Me- $\left[{ }^{2} \mathrm{H}_{6}\right]-\mathrm{ABA}$.

\section{5. $\quad$ RT-PCR analysis of RNA transcript during flooding}

The protocol of (Chan et al. 2004) was adopted with some modifications. By using TRIzol ${ }^{\mathrm{TM}}$ reagents the total RNAs were extracted from soybean leaves using the manufacturer standard protocol (Thermo Scientific; USA). For complementary DNA (cDNA) synthesis a total of 1 microgram RNA was used to reverse transcribed by using DiaStar ${ }^{\mathrm{TM}}$ RT kit (SolGent, Korea). The synthesized cDNA $(1 \mu \mathrm{l})$ was used as a template in quantitative real time PCR (qRT PCR) machine (Illumina, USA) using 2× Real-time PCR Master Mix (including SYBR ${ }^{\circledR}$ Green I BioFACT ${ }^{\mathrm{TM}}$ Korea). A no template control containing PCR-grade water instead of template DNA was used as negative control. Tow-step PCR was performed for 40 cycles of amplification using selected primers and actin. The PCR conditions were, polymerease activation at $95^{\circ} \mathrm{C}$ for $15 \mathrm{~min}$, 
246 denaturation at $95^{\circ} \mathrm{C}$ for $15 \mathrm{~s}$, and annealing and extension at $60^{\circ} \mathrm{C}$ for $30 \mathrm{~s}$. Actin was used as

247 reference to evaluate the expression level of our genes of interest (Table 1).

\subsection{Statistical analysis}

Each treatment was comprised of five pots, and each pot contained nine plants, thus making

251

252

253

254

255

256

257

258

259

260

261

262

263

264

265

266

267

\section{Results}

\subsection{Exogenous NO vs ROS antagonism during flooding stress}

Short-term flooding-induced ROS generation, especially superoxide anion, is a common phenomenon. The results of superoxide anion accumulation displayed varying responses of plants to $\mathrm{SNO}$ and CySNO treatment and duration of flooding stress. Significantly low level of superoxide anions had accumulated in Daewon plants treated with SNP and CySNO before the flooding stress. We recorded $13 \%$ and $20 \%$ decrease in superoxide anions in these plants after $3 \mathrm{~h}$ and $6 \mathrm{~h}$ of flooding, compared to control flooded plants (Fig. 1A). A similar trend was observed in Pungsannamul cultivars that were subjected to flooding for $3 \mathrm{~h}$, in which a $15 \%$ and $44 \%$ decrease in superoxide anion was recorded in plants treated with SNP and CySNO, respectively. 
268 Similarly, SNP and CySNO application also reduced the accumulation of superoxide anion by

$26911 \%$ and $46 \%$ after $6 \mathrm{~h}$ of flooding stress (Fig. 1B).

270 The glutathione-related antioxidant system is known to play a vital role in counteracting

271 ROS generation. Our results demonstrated a significant increase in the accumulation of reduced

272 glutathione content after flooding. However, plants treated with either of the SNO and CySNO as

273 NO-donors showed a significant decrease in reduced glutathione content. For example, reduced

274 glutathione contents were reduced by $14 \%$ and $21 \%$ in Daewon cultivars treated with SNP and

275 CySNO, respectively, after $3 \mathrm{~h}$ of flooding (Fig. 2A). Continued exposure to flooding maintained

276 a greater accumulation of reduced glutathione in Daewon as compared to the non-flooded control

277 (Cont.) plants. However, in SNP and CySNO treatments, a significant reduction in the reduced 278 glutathione level (ranging from 16\% to 24\%) was observed in the Daewon cultivar after $6 \mathrm{~h}$ of 279 flooding stress (Fig. 2A).

Flooding stress ( $3 \mathrm{~h}$ and $6 \mathrm{~h}$ ) also caused a greater accumulation of reduced glutathione in the Pungsannamul soybean cultivar. The Pungsannamul soybean cultivar showed significantly greater $(23 \%)$ reduced glutathione accrual in SNP and CySNO treated plants, respectively, after 3 $\mathrm{h}$ of flooding stress (Fig. 2B). The continued exposure to flooding $(6 \mathrm{~h})$ influenced the Pungsannamul soybean plants to synthesize more reduced glutathione compared to non-flooding control plants and $3 \mathrm{~h}$ stress. The SNP treatment significantly reduced (10\%) the synthesis of reduced glutathione after $6 \mathrm{~h}$ of flooding stress as compared to control flood treatments. CySNO, on the other hand, demonstrated a significantly larger $(18.1 \%)$ content of reduced glutathione in the Pungsannamul cultivar (Fig. 2B). 

stress compared to normal growth conditions in Daewon plants. However, during the initial $3 \mathrm{~h}$ of flooding stress, whole ABA contents were significantly reduced (10\% to $26 \%$ ) by SNP and CySNO as compared to plants grown under flood conditions (Fig. 3A). However, with the continued exposure to flood stress $(6 \mathrm{~h})$, the endogenous whole ABA content sharply increased CySNO induced a significant decline (19\% to $21 \%$ ) in whole ABA biosynthesis (Fig. 3A). cultivar than in the Daewon cultivar. The whole ABA content was significantly higher (3 fold) in the control flooded plants than in non-flooding control plants. Compared to control, whole ABA contents in Pungsannamul were significantly reduced by SNP and CySNO application (11\% and $14 \%$, respectively). After $6 \mathrm{~h}$ of treatment, the whole ABA content sharply increased (63\%) in the control flooded treatment, although SNP and CySNO-treated plants accumulated significantly less ABA (14\%).

\subsection{Modulation of endogenous S-Nitrosothiols by exogenous NO donors under}

\section{flooding stress.}

The endogenous S-Nitrosothiols (SNOs) were quantified in the shoots of both soybean

plant however the SNO accumulated significantly in Daewon plants in response to CySNO and 
313 flooded (Fig. 4A). . After $6 \mathrm{~h}$ of flooding, SNP and CySNO application showed significantly

314 reduced $7.66 \%$ and $10.61 \%$ endogenous SNO levels in Daewon cultivar (Fig. 4A).

315 Interestingly, endogenous SNO levels differed between Daewon and Pungsannamul

316 cultivars during flooding, which could be attributed to the variation in their physiology and genetic

317 response to flooding. In pungsannamul, compared to control treatment a significant higher

318 accumulation of SNO level were observed in flooded plant (233.21\%) however in control flooded,

319 SNP and CySNO the endogenous SNO levels were detected in moderate to low ranges during $3 \mathrm{~h}$

320 of flooding stress (Fig. 4B). In SNP and CySNO treatments the SNO level were significantly

321 increased from 30.81 to $53.84 \%$. After $6 \mathrm{~h}$ of flooding stress, significantly higher SNO content

$322(67 \%-140 \%)$ had accumulated in the aerial parts of Pungsannamul in response to SNP and CySNO

323 treatments as compared to the control flooding (Fig. 4B).

\subsection{Molecular analogy of exogenously applied-NO with SNO-related gene} expression during flooding stress

Cellular SNO levels are controlled by a key enzyme $S$-nitrosoglutathione reductase (GSNOR)

(Feechan et al. 2005). To observe whether flooding-induced SNO levels are regulated by GSNOR, we examined transcript accumulation of soybean GSNORl (AT5G43940) in plants of both soybean cultivars after flooding stress alone and in those treated with SNO and CySNO as NO donors. The Daewon cultivar showed a lower expression of GSNORl after $3 \mathrm{~h}$ of flooding, except in the CySNO treatment in which a significantly greater (2.1 fold) transcript accumulation of GSNOR 1 was observed. However, after $6 \mathrm{~h}$ of flooding, the GNSOR1 transcript accumulation was significantly increased (2.9 fold) by SNP treatment as compared to the CySNO and control 
335 treatments (Fig. 5A). During the SNP and CySNO treatments, the Pungsannamul cultivar

336 demonstrated a significantly increased transcript accumulation of GSNOR1 (1.2 to 2.2 fold,

337 respectively) as compared to the control after $3 \mathrm{~h}$ of flooding stress. This suggests a positive

338 regulation of GSNOR1 in modulating SNO levels under flooding stress. In contrast, there was no

339 significant difference in GSNOR transcript accumulation at $6 \mathrm{~h}$ post flooding stress (Fig. 5B).

340 To further understand the possible route of flooding-induced NO production, we examined

341 the transcript accumulation of NOX1 (AT5G33320) and NR (AT1G37130). In the Daewon

342 cultivar, the expression of $N O X 1$ was reduced overtime in response to both SNP- and CySNO-

343 treated plants as compared to the control (Fig. 5C). However, in the Pungsannamul cultivar, SNP

344 and CySNO treatments induced significantly increased ( 0.6 to 1.8 fold) levels of the NOX1

345 transcripts compared to the control after $3 \mathrm{~h}$ of flooding (Fig. 5D). Conversely, these transcript

346 levels were significantly obscured after $6 \mathrm{~h}$ of flooding.

347 In the case of $N R$, at $6 \mathrm{~h}$ post-flooding stress SNP and CySNO treatments showed either

348 reduced or similar expression levels in comparison with the non-flooded and flooded controls (Fig.

349 5E). NR activation was predominant in the non-flooded Pungsannamul control as compared to

350 CySNO and SNP treatments. $N R$ transcripts were significantly higher in the SNP treatment

351 compared to CySNO treatments during $3 \mathrm{~h}$ and $6 \mathrm{~h}$ of flooding periods but were significantly lower

352 in the non-flooded plants (Fig. 5F). Additionally, the CySNO treatment demonstrated a gradual

353 increase in NR transcript accumulation in both cultivars (Fig. 5E and F), whereas the opposite trend

354 was observed for GSNOR. 


\subsection{ABA-related transcript accumulation in response to flooding stress}

One of the key consequences of water stress is the re-distribution and synthesis of ABA that regulates stomatal movements. NO is reported to be involved in ABA-mediated stomatal changes

361 (Garcia-Mata \& Lamattina 2002). In this regard, we examined the transcript accumulation of Timing of $C A B$ expression 1 (TOC1) and ABA-receptor (ABAR) to understand NO-induced transcriptional changes during flooding stress. Our results showed reduced transcript accumulation of $A B A R$ compared to control plants in the Daewon soybean cultivar (Fig. 6A). Similarly, TOC1

365

366

367

\section{6} showed a decrease (1.2 fold) in transcript accumulation in Daewon soybean plants treated with exogenous SNP after $6 \mathrm{~h}$ of flooding stress compared to $3 \mathrm{~h}$ flooding stress and the non-flooded control plants (Fig. 6B).

We additionally studied the expression level of $T O C 1$ and $A B A R$ in the Pungsannamul soybean cultivar and observed no significant difference in $A B A R$ expression level at $3 \mathrm{~h}$ of flooding stress. However, reduced transcript accumulation was observed for all treatments at $6 \mathrm{~h}$ of flooding compared to the non-flooding control plants (Fig. 6C). The transcript accumulation of TOC1 showed that at $3 \mathrm{~h}$ of flooding stress the expression of TOCl was induced only in plants treated with exogenous SNP and CySNO compared to control plants. In contrast, the transcript accumulation of TOCl was significantly induced at $6 \mathrm{~h}$ of flooding in both $\mathrm{NO}$ treated plants compared to the control plants (Fig. 6D). 


\section{Discussion}

380

Recent studies have demonstrated that exogenous application of SNP and CySNO induces

381

382

383

384

385

386

387

388

389

390

391

392

393

394

395

396

397

398

399

400

401

abiotic stress tolerance traits in plants, typically due to the activation of antioxidant metabolites or enzymes such as glutathione's (Esringu et al. 2016; Jian et al. 2016). In the present study, the exoSNP and CySNO as NO donor displayed a similar trend of glutathione synthesis during $3 \mathrm{~h}$ and 6 $\mathrm{h}$ of flooding stress in Daewon plants, while the opposite was observed in the Pungsannamul cultivar. In the Daewon cultivar, glutathione synthesis increased during $3 \mathrm{~h}$ and $6 \mathrm{~h}$ of flooding but application of SNP and CySNO reduced glutathione content suggesting an adoption of defensive strategy to overcome oxidative stress. In contrast, Pungsannamul plants responded to oxidative stress by increasing glutathione synthesis, except in the SNP treatment. These results demonstrate the importance of SNP in the modulation of stress-aversion strategies. This was further validated by the results of superoxide anion content, as reduced oxidants were observed in SNP and CySNO treatment after $3 \mathrm{~h}$ and $6 \mathrm{~h}$ of flooding stress. For instance, SNP application was shown to reduce the oxidative stress in some plants through the regulation of antioxidants (Esringu et al. 2016; Innocenti et al. 2007; Jian et al. 2016). Glutathione, on the other hand, is a known determinant of cellular redox homeostasis (Cheng et al. 2015) and often increases with the level and intensity of stress (Noctor et al. 2012). In the current study, glutathione increased with the inception of hypoxic conditions but later decreased with exo-CySNO regulators in Daewon soybean, suggesting an improved defensive mechanism by both exogenous and endogenous factors. A reduction of glutathione post-anoxia has also been suggested by (Arbona et al. 2017).

Endogenous ABA, on the other hand, is known to be involved in signalling cascades related to plant defence and abiotic stress modulation in various crop plants including soybean (Yin et al. 2017). The ABA signalling pathway is composed of several elements including receptors, 
402 transcription factors, secondary messengers such as $\mathrm{Ca}^{2+}$, ion transporters, hydrogen peroxide, and

403 nitric oxide (Zhao et al. 2016). ABA tends to increase during flooding stress and was reported in 404 Barbeton daisy, citrus plants, alfalfa, tobacco, pea, tomato, and apple (Arbona \& Gómez-Cadenas 405 2008; Bai et al. 2011; Castonguay et al. 1993; Else et al. 1995; Hurng et al. 1994; Jackson et al. 406 1988; Olivella et al. 2000) under flooding stress. The ABA response to flooding may differ and 407 depend on the plant species and duration of flooding. Other studies reported that flooding stress 408 have associated ABA accumulation with an increase in reactive oxygen species (ROS), in Glycine $409 \max$ L roots (Vantoai \& Bolles 1991), Zea mays L. leaves (Yan et al. 1996), and Triticum aestivum 410 L. roots (Biemelt et al. 2000). The results of the present study showed that NO sources (SNP and 411 CySNO) significantly decreased ABA accumulation in the Daewon and Pungsannamul soybean. 412 These results are also consistent with the transcript analysis of TOC1 and $A B A R$ genes during 413 flooding stress. Initially identified in Arabidopsis, Legnaioli et al. (2009) suggested that TOC1 414 binds to the promoter of ABA-related gene (thus called ABAR). Interestingly this binding is 415 regulated by $\mathrm{ABA}$ or in other words $\mathrm{ABA}$ induction of TOC1 helps in binding with $A B A R$. 416 Legnaioli et al. (2009) also confirmed this through functional genomics study and found that $A B A R$ 417 knocked down lines were not able to induced TOC1 to bind with $A B A R$ and further suggested both $A B A R$ and TOC1 role in drought regulation. Later their orthologs in Soybean were found to 419 mediate flooding and drought responses in soybean as well Syed et al. (2015). Both genes are 420 related to the circadian expression of abiotic stress phases, during which both genes exhibit a 421 reciprocal regulation during stress conditions. Our results revealed that, upon exo-NO application, 422 the $A B A R$ was up-regulated in the initial $3 \mathrm{~h}$ flooding but showed significant down regulation after $4236 \mathrm{~h}$ post-flooding. Similarly, differential response was observed for both cultivars in terms of 424 TOC1 expression after flooding stress. TOC1 showed decreased transcript accumulation in 
425 Daewon while increased in Pungsannamul cultivar after $3 \mathrm{~h}$ of flooding stress. TOC1 is acutely

426 induced by ABA, and this induction advances the phase of TOC1 binding and modulates $A B A R$

427 circadian expression (Legnaioli et al. 2009); Syed et al. (2015). This suggests that exo-SNP can

428 regulate soybean plant responses by influencing ABA and possibly regulating the transcription of

$429 A B A R$ and TOC1 during short-term flooding stress (Arbona et al. 2017). are controlled predominantly by S-nitrosoglutathione reductase 1 (GSNOR1) which turns over the natural NO donor, S-nitrosoglutathione (GSNO) (Feechan et al. 2005; Malik et al. 2011; Yun et al. 2016). In the absence of the GSNORI function, GSNO accumulates, leading to an overall rise in total cellular SNOs. The present results demonstrated an interesting response by increasing endogenous NO levels after $3 \mathrm{~h}$ relative to $6 \mathrm{~h}$ in Daewon soybean cultivar. In Pungsannamul soybean, higher level of endogenous NO was observed after $3 \mathrm{~h}$ and $6 \mathrm{~h}$ of flooding in shoots. These results suggest that exo-SNP and CysNO can mitigate the flooding stress-induced NO production with an exposure period in the Daewon cultivar, whereas in the Pungsannamul cultivar, the shoots would not able to counteract the stress. Nitric oxide transfer its bioactivity through posttranslational modification called $S$-nitrosylation; the attachment of NO moiety with exposed cysteine thiol of other proteins to form S-nitrosothiol (SNOs) thereby regulating proteins functions. Therefore, the level of SNOs in cell may suggest the level of nitrosative stress and that is why its measurement is key parameter in number of studies involving role of NO in plants (Feechan et al.

447 2005; Imran et al. 2016; Imran et al. 2018; Yun et al. 2011). We therefore sought to determine 
448 SNO levels as reactive nitrogen species to assess the magnitude of nitrosative stress in NO-donors 449 treated samples after flooding conditions. present study also indicates the effect of exo-SNP and CySNO on plant growth. We did not notice any differential changes in plant morphology due to short-term flooding stress, although the endogenous NO levels significantly varied in Daewon and Pungsannamul after $3 \mathrm{~h}$ and $6 \mathrm{~h}$ postflooding periods. At $3 \mathrm{~h}$ post flooding stress the accumulation of SNO in SNP and CySNO treated plants increased. However, at $6 \mathrm{~h}$ post stress the SNO contents decreased suggesting that no more SNP or CySNO released NO could be accommodated in the cell as there is enough SNOs accumulated. Furthermore, the differential accumulation of NO in response to SNP could also be attributed to the limitations in use of SNP as NO donor. Contrasting reports are published mentioning both pros and cons of SNP as NO donor. In a study using germination assays in response to SNP and cyanide da Silva et al. (2019) reported that cyanide released from SNP can increase germination of Senna macranthera. On the other hand reports suggested that cyanide release from SNP can reduce the photochemical activity of photosystem II thereby affecting plant productivity (Wodala et al. 2010). However, the difference in the reduction of SNOs might be due to the different No release by different NO donors which is also described by (He \& Frost 2016). Hussain et al. (2016) used it as NO donor to see global changes in gene expression and identified more than 6000 genes that should significant differential expression. Similarly, almost similar treatment of CySNO was used in other studies as well (Lam et al. 2010; Martinez-Ruiz \& Lamas 2004) etc. Increased NO levels in both cultivars may indicate the transduction of NO bioactivity 469 in plants after short-term flooding stress. 
471 (Feechan et al. 2005). The enzyme GSNOR play role in maintaining this hemostasis (Leterrier et

472 al. 2011). GSNOR1 predominantly regulates $S$-nitrosylation via trans-nitrosylation (Foster et al.

473 2009), which involves the direct transfer of NO from GSNO to its target cysteine (Cys) residue.

474 In the current study, it was coupled with transcript accumulation and reduction of GSNORI in

475 response to $3 \mathrm{~h}$ and $6 \mathrm{~h}$ post-flooding stress periods in Daewon soybean. However, in 476 Pungsannamul soybean plants, the exogenous SNP and CySNO reduced the transcript 477 accumulation of GSNOR1 with the exposure of flooding stress. In the case of $N R$ and $N O X$, a 478 similar reduction in transcript accumulation was observed in Pungsannamul soybean plants. In 479 Daewon plants, however, a reverse transcript expression was shown for $N R$ and $N O X$ genes. These 480 findings were unexpected, as in previous work the NOX mutants exhibited increased NO 481 accumulation in Arabidopsis thaliana (Guo et al. 2003), which had negatively regulated the 482 examined morphological responses (He et al. 2004). This is also in line with the ABA results in 483 Daewon soybean plants suggesting that $N R$, which determines the NO production in plants, is 484 critical to ABA-induced stomatal closure (Kwon et al. 2012; Yun et al. 2016; Zhao et al. 2016). 485 The Pungsannamul soybean plants expressed the lowest level of gene expression of GSNOR1, NR, 486 and NOX, suggesting a contribution towards the loss of potential function against prolonged

487 flooding stress, which was also confirmed from a previous study involving Arabidopsis thaliana. 488 Although efforts have been made to understand the role of SNO during innate immunity in plants 489 against disease resistance, little is known about the comprehensive regulations of SNO synthesis 490 and transcript accumulation under flooding stress. Our study urges that more attention be given to 491 the important inter-junctions related to the role of NO in stress signalling in plants.

\section{Conclusion}


494 glutathione activity and endogenous ABA over time, whereas increases S-nitorosothiols levels. 495 Exo SNP and CySNO reduced ROS production but enhanced superoxide anion accumulation. The 496 transcript accumulation of GSNOR1, NOX1, and $N R$ were found in higher amounts under flooding 497 stress as compared to control. Current results demonstrate an active role of exo SNP and CySNO 498 during short-exposure to flooding stress. The exogenous SNP and CySNO impinge a variety of 499 biochemical and transcriptional changes in soybean. Such changes have been suggested important 500 to reprograms the stress responses by plant to maintain a study growth potential during shorter or 501 longer flooding excursion.

502

\section{Abbreviations}

504 NO: Nitric oxide; TOC: Timing of CAB expression; GSNOR1: S-Nitroso Glutathione Reductase1;

505 NR: Nitrate Reductase; SNP: Sodium Nitroprusside; CySNO: S-Nitroso L-Cysteine; ABAR: ABA506 receptor; ABA: Abscisic acid; GA: Gibberellin; SNO: $S$-nitrosothiol. 
509

510

511

512

513

514

515

516

517

518

519

520

521

522

523

524

525

526

527

528

529

530

531

532

533

534

535

536

537

538

539

540

541

542

543

544

545

546

547

548

549

550

551

552

553

\section{References}

Alderton WK, Cooper CE, and Knowles RG. 2001. Nitric oxide synthases: structure, function and inhibition. Biochemical Journal 357:593-615.

Alfieri L, Feyen L, Salamon P, Thielen J, Bianchi A, Dottori F, and Burek P. 2016. Modelling the socioeconomic impact of river floods in Europe. Natural Hazards and Earth System Sciences 16:14011411.

Arbona V, and Gómez-Cadenas A. 2008. Hormonal Modulation of Citrus Responses to Flooding. Journal of Plant Growth Regulation 27:241. 10.1007/s00344-008-9051-x

Arbona V, Zandalinas SI, Manzi M, Gonzalez-Guzman M, Rodriguez PL, and Gomez-Cadenas A. 2017. Depletion of abscisic acid levels in roots of flooded Carrizo citrange (Poncirus trifoliata L. Raf. $x$ Citrus sinensis L. Osb.) plants is a stress-specific response associated to the differential expression of PYR/PYL/RCAR receptors. Plant Mol Biol 93:623-640. 10.1007/s11103-017-0587-7

Asaf S, Khan AL, Khan MA, Imran QM, Yun B-W, and Lee I-J. 2017. Osmoprotective functions conferred to soybean plants via inoculation with Sphingomonas sp. LK11 and exogenous trehalose. Microbiol Res 205:135-145. https://doi.org/10.1016/j.micres.2017.08.009

Asgher M, Per TS, Masood A, Fatma M, Freschi L, Corpas FJ, and Khan NA. 2016. Nitric oxide signaling and its crosstalk with other plant growth regulators in plant responses to abiotic stress. Environmental Science and Pollution Research:1-13. 10.1007/s11356-016-7947-8

Bai T, Yin R, Li C, Ma F, Yue Z, and Shu H. 2011. Comparative Analysis of Endogenous Hormones in Leaves and Roots of Two Contrasting Malus Species in Response to Hypoxia Stress. Journal of Plant Growth Regulation 30:119-127. 10.1007/s00344-010-9173-9

Bailey-Serres J, Lee SC, and Brinton E. 2012. Waterproofing Crops: Effective Flooding Survival Strategies. Plant Physiology 160:1698-1709. 10.1104/pp.112.208173

Bailey-Serres J, and Voesenek LACJ. 2008. Flooding stress: Acclimations and genetic diversity. Annual review of plant biology 59:313-339. 10.1146/annurev.arplant.59.032607.092752

Biemelt S, Keetman U, Mock H-P, and Grimm B. 2000. Expression and activity of isoenzymes of superoxide dismutase in wheat roots in response to hypoxia and anoxia. Plant Cell Environ 23:135-144. doi:10.1046/j.1365-3040.2000.00542.x

Burniston MT, and Wilson DJ. 2008. Radioiodine ablation outcomes after imaging with I-123 or I-131: Is no news good news? Journal of Nuclear Medicine 49:166-166. 10.2967/jnumed.107.047076

Castonguay Y, Nadeau P, and Simard RR. 1993. Effects of flooding on carbohydrate and ABA levels in roots and shoots of alfalfa. Plant Cell Environ 16:695-702. doi:10.1111/j.13653040.1993.tb00488.x

Chan C-X, Teo S-S, Ho C-L, Othman RY, and Phang S-M. 2004. Optimisation of RNA extraction from Gracilaria changii (Gracilariales, Rhodophyta). Journal of Applied Phycology 16:297-301. 10.1023/B:JAPH.0000047782.20940.de

Cheng MC, Ko K, Chang WL, Kuo WC, Chen GH, and Lin TP. 2015. Increased glutathione contributes to stress tolerance and global translational changes in Arabidopsis. Plant Journal 83:926-939. 10.1111/tpj.12940

Correa-Aragunde N, Graziano M, and Lamattina L. 2004. Nitric oxide plays a central role in determining lateral root development in tomato. Planta 218:900-905. 10.1007/s00425-003-1172-7

da Silva AL, Pinheiro DT, Borges EEDE, da Silva LJ, and Dias DCFD. 2019. Effect of cyanide by sodium nitroprusside (SNP) application on germination, antioxidative system and lipid peroxidation of Senna macranthera seeds under saline stress. Journal of Seed Science 41:86-96. 10.1590/2317$1545 \mathrm{v} 41 \mathrm{n} 1213725$ 
554

555

556

557

558

559

560

561

562

563

564

565

566

567

568

569

570

571

572

573

574

575

576

577

578

579

580

581

582

583

584

585

586

587

588

589

590

591

592

593

594

595

596

597

598

599

600

601

de Sousa A, AbdElgawad H, Asard H, Pinto A, Soares C, Branco-Neves S, Braga T, Azenha M, Selim S, Al Jaouni S, Fidalgo F, and Teixeira J. 2017. Metalaxyl Effects on Antioxidant Defenses in Leaves and Roots of Solanum nigrum L. Frontiers in Plant Science 8. 10.3389/fpls.2017.01967

Delledonne M, Xia YJ, Dixon RA, and Lamb C. 1998. Nitric oxide functions as a signal in plant disease resistance. Nature 394:585-588.

Doke N. 1983. Involvement of superoxide anion generation in the hypersensitive response of potato tuber tissues to infection with an incompatible race of Phytophthora infestans and to the hyphal wall components. Physiological Plant Pathology 23:345-357. https://doi.org/10.1016/00484059(83)90019-X

Dordas C. 2015. Nitric Oxide and Plant Hemoglobins Improve the Tolerance of Plants to Hypoxia. Nitric Oxide Action in Abiotic Stress Responses in Plants: Springer, 115-128.

Durner J, Wendehenne D, and Klessig DF. 1998. Defense gene induction in tobacco by nitric oxide, cyclic GMP, and cyclic ADP-ribose. Proceedings of the National Academy of Sciences 95:10328-10333. 10.1073/pnas.95.17.10328

Durzan DJ, and Pedroso MC. 2002a. Nitric oxide and reactive nitrogen oxide species in plants. Biotechnology \& Genetic Engineering Reviews, Vol 19 19:293-337.

Durzan DJ, and Pedroso MC. 2002b. Nitric oxide and reactive nitrogen oxide species in plants. Biotechnol Genet Eng Rev 19:293-337.

Ellman GL. 1959. Tissue sulfhydryl groups. Archives of Biochemistry and Biophysics 82:70-77. https://doi.org/10.1016/0003-9861(59)90090-6

Else MA, Hall KC, Arnold GM, Davies WJ, and Jackson MB. 1995. Export of Abscisic Acid, 1Aminocyclopropane-1-Carboxylic Acid, Phosphate, and Nitrate from Roots to Shoots of Flooded Tomato Plants (Accounting for Effects of Xylem Sap Flow Rate on Concentration and Delivery). Plant Physiology 107:377-384. 10.1104/pp.107.2.377

Esringu A, Aksakal O, Tabay D, and Kara AA. 2016. Effects of sodium nitroprusside (SNP) pretreatment on UV-B stress tolerance in lettuce (Lactuca sativa L.) seedlings. Environmental Science and Pollution Research 23:589-597. 10.1007/s11356-015-5301-1

Fan X, Naz M, Fan X, Xuan W, Miller AJ, and Xu G. 2017. Plant nitrate transporters: from gene function to application. Journal of Experimental Botany. 10.1093/jxb/erx011

Feechan A, Kwon E, Yun B-W, Wang Y, Pallas JA, and Loake GJ. 2005. A central role for S-nitrosothiols in plant disease resistance. Proceedings of the National Academy of Sciences 102:8054-8059.

Foster MW, Liu LM, Zeng M, Hess DT, and Stamler JS. 2009. A Genetic Analysis of Nitrosative Stress. Biochemistry 48:792-799. 10.1021/bi801813n

Gajewska E, and Skłodowska M. 2007. Effect of nickel on ROS content and antioxidative enzyme activitiesin wheat leaves. BioMetals 20:27-36. 10.1007/s10534-006-9011-5

Garcia-Mata C, and Lamattina L. 2002. Nitric oxide and abscisic acid cross talk in guard cells. Plant Physiology 128:790-792. 10.1104/pp.011020

Gasch P, Fundinger M, Muller JT, Lee T, Bailey-Serres J, and Mustroph A. 2016. Redundant ERF-VII Transcription Factors Bind to an Evolutionarily Conserved cis-Motif to Regulate HypoxiaResponsive Gene Expression in Arabidopsis. Plant Cell 28:160-180. 10.1105/tpc.15.00866

Gibbs DJ, Lee SC, Isa NM, Gramuglia S, Fukao T, Bassel GW, Correia CS, Corbineau F, Theodoulou FL, Bailey-Serres J, and Holdsworth MJ. 2011. Homeostatic response to hypoxia is regulated by the $\mathrm{N}$-end rule pathway in plants. Nature 479:415-418. 10.1038/nature10534

Gibbs DJ, Md Isa N, Movahedi M, Lozano-Juste J, Mendiondo GM, Berckhan S, Marin-de la Rosa N, Vicente Conde J, Sousa Correia C, Pearce SP, Bassel GW, Hamali B, Talloji P, Tome DF, Coego A, Beynon J, Alabadi D, Bachmair A, Leon J, Gray JE, Theodoulou FL, and Holdsworth MJ. 2014. Nitric oxide sensing in plants is mediated by proteolytic control of group VII ERF transcription factors. Mol Cell 53:369-379. 10.1016/j.molcel.2013.12.020

Peer] reviewing PDF | (2018:12:33773:2:1:NEW 5 Aug 2019) 
602

603

604

605

606

607

608

609

610

611

612

613

614

615

616

617

618

619

620

621

622

623

624

625

626

627

628

629

630

631

632

633

634

635

636

637

638

639

640

641

642

643

644

645

646

647

648

Guo F-Q, Okamoto M, and Crawford NM. 2003. Identification of a Plant Nitric Oxide Synthase Gene Involved in Hormonal Signaling. Science 302:100-103. 10.1126/science.1086770

Gupta KJ, Lee CP, and Ratcliffe RG. 2016. Nitrite Protects Mitochondrial Structure and Function under Hypoxia. Plant and Cell Physiology. 10.1093/pcp/pcw174

Hasanuzzaman M, Hossain MA, and Fujita M. 2012. Exogenous selenium pretreatment protects rapeseed seedlings from cadmium-induced oxidative stress by upregulating antioxidant defense and methylglyoxal detoxification systems. Biol Trace Elem Res 149:248-261. 10.1007/s12011012-9419-4

He WL, and Frost MC. 2016. Direct measurement of actual levels of nitric oxide (NO) in cell culture conditions using soluble NO donors. Redox Biology 9:1-14. 10.1016/j.redox.2016.05.002

He Y, Tang R-H, Hao Y, Stevens RD, Cook CW, Ahn SM, Jing L, Yang Z, Chen L, Guo F, Fiorani F, Jackson RB, Crawford NM, and Pei Z-M. 2004. Nitric Oxide Represses the Arabidopsis Floral Transition. Science 305:1968-1971. 10.1126/science.1098837

Hinz M, Wilson IW, Yang J, Buerstenbinder K, Llewellyn D, Dennis ES, Sauter M, and Dolferus R. 2010. Arabidopsis RAP2.2: an ethylene response transcription factor that is important for hypoxia survival. Plant Physiol 153:757-772. 10.1104/pp.110.155077

Hurng WP, Lur HS, Liao C-K, and Kao CH. 1994. Role of Abscisic Acid, Ethylene and Polyamines in Flooding-Promoted Senescence of Tobacco Leaves. Journal of Plant Physiology 143:102-105. https://doi.org/10.1016/S0176-1617(11)82104-8

Hussain A, Mun BG, Imran QM, Lee SU, Adamu TA, Shahid M, Kim KM, and Yun BW. 2016. Nitric oxide mediated transcriptome profiling reveals activation of multiple regulatory pathways in Arabidopsis thaliana. Frontiers in Plant Science 7. ARTN 975

10.3389/fpls.2016.00975

Imran QM, Falak N, Hussain A, Mun B-G, Sharma A, Lee S-U, Kim K-M, and Yun B-W. 2016. Nitric oxide responsive heavy metal-associated gene AtHMAD1 contributes to development and disease resistance in Arabidopsis thaliana. Frontiers in Plant Science 7.

Imran QM, Hussain A, Mun BG, Lee SU, Asaf S, Ali MA, Lee IJ, and Yun BW. 2018. Transcriptome wide identification and characterization of NO-responsive WRKY transcription factors in Arabidopsis thaliana L. Environmental and Experimental Botany 148:128-143.

10.1016/j.envexpbot.2018.01.010

Innocenti G, Pucciariello C, Le Gleuher M, Hopkins J, de Stefano M, Delledonne M, Puppo A, Baudouin E, and Frendo P. 2007. Glutathione synthesis is regulated by nitric oxide in Medicago truncatula roots. Planta 225:1597-1602. 10.1007/s00425-006-0461-3

Islam F, Yasmeen T, Arif MS, Riaz M, Shahzad SM, Imran Q, and Ali I. 2016. Combined ability of chromium ( $\mathrm{Cr}$ ) tolerant plant growth promoting bacteria (PGPB) and salicylic acid (SA) in attenuation of chromium stress in maize plants. Plant physiology and biochemistry : PPB 108:456-467. 10.1016/j.plaphy.2016.08.014

Jackson MB, and Colmer TD. 2005. Response and adaptation by plants to flooding stress - Preface. Annals of Botany 96:501-505. 10.1093/aob/mci205

Jackson MB, Young SF, and Hall KC. 1988. Are Roots a Source of Abscisic Acid for the Shoots of Flooded Pea Plants? J Exp Bot 39:1631-1637. 10.1093/jxb/39.12.1631

Jday A, Ben Rejeb K, Slama I, Saadallah K, Bordenave M, Planchais S, Savoure A, and Abdelly C. 2016. Effects of exogenous nitric oxide on growth, proline accumulation and antioxidant capacity in Cakile maritima seedlings subjected to water deficit stress. Functional Plant Biology 43:939-948. 10.1071/FP15363

Jensen DE, Belka GK, and Du Bois GC. 1998. S-Nitrosoglutathione is a substrate for rat alcohol dehydrogenase class III isoenzyme. Biochemical Journal 331:659-668. DOI 10.1042/bj3310659 
649

650

651

652

653

654

655

656

657

658

659

660

661

662

663

664

665

666

667

668

669

670

671

672

673

674

675

676

677

678

679

680

681

682

683

684

685

686

687

688

689

690

691

692

693

694

695

Jian W, Zhang DW, Zhu F, Wang SX, Pu XJ, Deng XG, Luo SS, and Lin HH. 2016. Alternative oxidase pathway is involved in the exogenous SNP-elevated tolerance of Medicago truncatula to salt stress. Journal of Plant Physiology 193:79-87. 10.1016/j.jplph.2016.01.018

Kamboj JS, Browning G, Blake PS, Quinlan JD, and Baker DA. 1999. GC-MS-SIM analysis of abscisic acid and indole-3-acetic acid in shoot bark of apple rootstocks. Plant Growth Regulation 28:21-27. 10.1023/a:1006299414481

Khan AL, Bilal S, Halo BA, Al-Harrasi A, Khan AR, Waqas M, Al-Thani GS, Al-Amri I, Al-Rawahi A, and Lee IJ. 2017. Bacillus amyloliquefaciens BSL16 improves phytoremediation potential of Solanum lycopersicum during copper stress. Journal of Plant Interactions 12:550-559. 10.1080/17429145.2017.1397203

Kwon E, Feechan A, Yun B-W, Hwang B-H, Pallas J, Kang J-G, and Loake G. 2012. AtGSNOR1 function is required for multiple developmental programs in Arabidopsis. Planta 236:887-900. 10.1007/s00425-012-1697-8

Lam YW, Yuan Y, Isaac J, Babu CVS, Meller J, and Ho SM. 2010. Comprehensive Identification and Modified-Site Mapping of S-Nitrosylated Targets in Prostate Epithelial Cells. Plos One 5. ARTN e9075

10.1371/journal.pone.0009075

Legnaioli T, Cuevas J, and Mas P. 2009. TOC1 functions as a molecular switch connecting the circadian clock with plant responses to drought. Embo Journal 28:3745-3757. 10.1038/emboj.2009.297

Leterrier M, Chaki M, Airaki M, Valderrama R, Palma JM, Barroso JB, and Corpas FJ. 2011. Function of Snitrosoglutathione reductase (GSNOR) in plant development and under biotic/abiotic stress. Plant Signal Behav 6:789-793.

Licausi F, Kosmacz M, Weits DA, Giuntoli B, Giorgi FM, Voesenek LA, Perata P, and van Dongen JT. 2011. Oxygen sensing in plants is mediated by an $\mathrm{N}$-end rule pathway for protein destabilization. Nature 479:419-422. 10.1038/nature10536

Liu P, Sun F, Gao R, and Dong H. 2012. RAP2.6L overexpression delays waterlogging induced premature senescence by increasing stomatal closure more than antioxidant enzyme activity. Plant Mol Biol 79:609-622. 10.1007/s11103-012-9936-8

Magalhaes JR, Monte DC, and D. D. 2000. Nitric oxide and ethylene emission in Arabidopsis thaliana. . Physiol Mol Biol Plants 6:117-127.

Malik SI, Hussain A, Yun BW, Spoel SH, and Loake GJ. 2011. GSNOR-mediated de-nitrosylation in the plant defence response. Plant Science 181:540-544. 10.1016/j.plantsci.2011.04.004

Manac'h-Little N, Igamberdiev AU, and Hill RD. 2005. Hemoglobin expression affects ethylene production in maize cell cultures. Plant physiology and biochemistry : PPB 43:485-489. 10.1016/j.plaphy.2005.03.012

Martinez-Ruiz A, and Lamas S. 2004. Detection and proteomic identification of S-nitrosylated proteins in endothelial cells. Archives of Biochemistry and Biophysics 423:192-199. 10.1016/j.abb.2003.12.006

Misra AN, Misra M, and Singh R. 2011. Nitric oxide ameliorates stress responses in plants. Plant Soil and Environment 57:95-100.

Mustafa G, and Komatsu S. 2014. Quantitative proteomics reveals the effect of protein glycosylation in soybean root under flooding stress. Frontiers in Plant Science 5. 10.3389/fpls.2014.00627

Neill S, Barros R, Bright J, Desikan R, Hancock J, Harrison J, Morris P, Ribeiro D, and Wilson I. 2008. Nitric oxide, stomatal closure, and abiotic stress. Journal of Experimental Botany 59:165-176. $10.1093 / \mathrm{jxb} / \mathrm{erm} 293$

Nemhauser JL, Hong F, and Chory J. 2006. Different plant hormones regulate similar processes through largely nonoverlapping transcriptional responses. Cell 126:467-475. 10.1016/j.cell.2006.05.050

Peer] reviewing PDF | (2018:12:33773:2:1:NEW 5 Aug 2019) 
696

697

698

699

700

701

702

703

704

705

706

707

708

709

710

711

712

713

714

715

716

717

718

719

720

721

722

723

724

725

726

727

728

729

730

731

732

733

734

735

736

737

738

739

740

741

742

Noctor G, Mhamdi A, Chaouch S, Han Y, Neukermans J, Marquez-Garcia B, Queval G, and Foyer CH. 2012. Glutathione in plants: an integrated overview. Plant Cell and Environment 35:454-484. 10.1111/j.1365-3040.2011.02400.x

O'Brien JA, and Benkova E. 2013. Cytokinin cross-talking during biotic and abiotic stress responses. Front Plant Sci 4:451. 10.3389/fpls.2013.00451

Olivella C, Biel C, Savé R, and Vendrell M. 2000. Hormonal and Physiological Responses of Gerbera jamesonii to Flooding Stress. HortScience 35:222-225.

Qi QG, Rose PA, Abrams GD, Taylor DC, Abrams SR, and Cutler AJ. 1998. (+)-abscisic acid metabolism, 3ketoacyl-coenzyme A synthase gene expression, and very-long-chain monounsaturated fatty acid biosynthesis in Brassica napus embryos. Plant Physiology 117:979-987. DOI 10.1104/pp.117.3.979

Rodriguez-Gamir J, Ancillo G, Gonzalez-Mas MC, Primo-Millo E, Iglesias DJ, and Forner-Giner MA. 2011. Root signalling and modulation of stomatal closure in flooded citrus seedlings. Plant Physiol Biochem 49:636-645. 10.1016/j.plaphy.2011.03.003

Sasidharan R, Hartman S, Liu ZG, Martopawiro S, Sajeev N, van Veen H, Yeung E, and Voeseneka LACJ. 2018. Signal Dynamics and Interactions during Flooding Stress. Plant Physiology 176:1106-1117. 10.1104/pp.17.01232

Shahzad R, Waqas M, Khan AL, Asaf S, Khan MA, Kang S-M, Yun B-W, and Lee I-J. 2016. Seed-borne endophytic Bacillus amyloliquefaciens RWL-1 produces gibberellins and regulates endogenous phytohormones of Oryza sativa. Plant Physiology and Biochemistry 106:236-243. https://doi.org/10.1016/j.plaphy.2016.05.006

Shi QH, Ding F, Wang XF, and Wei M. 2007. Exogenous nitric oxide protect cucumber roots against oxidative stress induced by salt stress. Plant Physiology and Biochemistry 45:542-550. 10.1016/j.plaphy.2007.05.005

Syed NH, Prince SJ, Mutava RN, Patil G, Li S, Chen W, Babu V, Joshi T, Khan S, and Nguyen HT. 2015. Core clock, SUB1, and ABAR genes mediate flooding and drought responses via alternative splicing in soybean. Journal of Experimental Botany 66:7129-7149. 10.1093/jxb/erv407

Talukdar D. 2013. Arsenic-induced oxidative stress in the common bean legume, Phaseolus vulgaris L. seedlings and its amelioration by exogenous nitric oxide. Physiology and Molecular Biology of Plants 19:69-79. 10.1007/s12298-012-0140-8

Tewari S, and Arora NK. 2016. 2 - Soybean Production Under Flooding Stress and Its Mitigation Using Plant Growth-Promoting Microbes A2 - Miransari, Mohammad. Environmental Stresses in Soybean Production. San Diego: Academic Press, 23-40.

Tunc-Ozdemir M, Miller G, Song LH, Kim J, Sodek A, Koussevitzky S, Misra AN, Mittler R, and Shintani D. 2009. Thiamin Confers Enhanced Tolerance to Oxidative Stress in Arabidopsis. Plant Physiology 151:421-432. 10.1104/pp.109.140046

Valderrama R, Corpas FJ, Carreras A, Fernández-Ocaña A, Chaki M, Luque F, Gómez-Rodríguez MV, Colmenero-Varea P, del Río LA, and Barroso JB. 2007. Nitrosative stress in plants. FEBS letters 581:453-461. http://dx.doi.org/10.1016/j.febslet.2007.01.006

Vantoai TT, and Bolles CS. 1991. Postanoxic Injury in Soybean (Glycine max) Seedlings. Plant Physiology 97:588-592.

Visser EJW, and Pierik R. 2007. Inhibition of root elongation by ethylene in wetland and non-wetland plant species and the impact of longitudinal ventilation. Plant Cell and Environment 30:31-38. 10.1111/j.1365-3040.2006.01601.x

Wang C, Deng PY, Chen LL, Wang XT, Ma H, Hu W, Yao NC, Feng Y, Chai RH, Yang GX, and He GY. 2013. A Wheat WRKY Transcription Factor TaWRKY10 Confers Tolerance to Multiple Abiotic Stresses in Transgenic Tobacco. Plos One 8. ARTN e65120

Peer] reviewing PDF | (2018:12:33773:2:1:NEW 5 Aug 2019) 
743

744

745

746

747

748

749

750

751

752

753

754

755

756

757

758

759

760

761

762

763

764

765

766

767

768

769

770

771

772

773

774

775

776

777

778

779 10.1371/journal.pone.0065120

Wang JZ, Wang Y, Lv Q, Wang L, Du J, Bao F, and He YK. 2017a. Nitric oxide modifies root growth by Snitrosylation of plastidial glyceraldehyde-3-phosphate dehydrogenase. Biochemical and Biophysical Research Communications 488:88-94. 10.1016/j.bbrc.2017.05.012

Wang T, Yang W, Xie Y, Shi D, Ma Y, and Sun X. 2017b. Effects of exogenous nitric oxide on the photosynthetic characteristics of bamboo (Indocalamus barbatus McClure) seedlings under acid rain stress. Plant Growth Regulation:1-10. 10.1007/s10725-016-0239-y

Wodala B, Ordog A, and Horvath F. 2010. The cost and risk of using sodium nitroprusside as a NO donor in chlorophyll fluorescence experiments. Journal of Plant Physiology 167:1109-1111. 10.1016/j.jplph.2010.03.013

Yan B, Dai Q, Liu X, Huang S, and Wang Z. 1996. Flooding-induced membrane damage, lipid oxidation and activated oxygen generation in corn leaves. Plant and Soil 179:261-268. 10.1007/bf00009336

Yin X, Hiraga S, Hajika M, Nishimura M, and Komatsu S. 2017. Transcriptomic analysis reveals the flooding tolerant mechanism in flooding tolerant line and abscisic acid treated soybean. Plant Mol Biol 93:479-496. 10.1007/s11103-016-0576-2

Yu M, Lamattina L, Spoel SH, and Loake GJ. 2014a. Nitric oxide function in plant biology: a redox cue in deconvolution. New Phytologist 202:1142-1156. 10.1111/nph.12739

Yu MD, Lamattina L, Spoel SH, and Loake GJ. 2014b. Nitric oxide function in plant biology: a redox cue in deconvolution. New Phytologist 202:1142-1156. 10.1111/nph.12739

Yun B-W, Feechan A, Yin M, Saidi NBB, Le Bihan T, Yu M, Moore JW, Kang J-G, Kwon E, Spoel SH, Pallas $J A$, and Loake GJ. 2011. S-nitrosylation of NADPH oxidase regulates cell death in plant immunity. Nature:264-268. http://www.nature.com/nature/journal/v478/n7368/abs/nature10427.html\#supplementaryinformation

Yun BW, Skelly MJ, Yin MH, Yu MD, Mun BG, Lee SU, Hussain A, Spoel SH, and Loake GJ. 2016. Nitric oxide and S-nitrosoglutathione function additively during plant immunity. New Phytologist 211:516-526. 10.1111/nph.13903

Zhang H, Tian H, Chen M, Xiong J, Cai H, and Liu Y. 2018. Transcriptome analysis reveals potential genes involved in flower pigmentation in a red-flowered mutant of white clover (Trifolium repens L.). Genomics 110:191-200.

Zhao CC, Cai SG, Wang YZ, and Chen ZH. 2016. Loss of nitrate reductases NIA1 and NIA2 impairs stomatal closure by altering genes of core ABA signaling components in Arabidopsis. Plant Signaling \& Behavior 11. UNSP e1183088

10.1080/15592324.2016.1183088 


\section{Figure 1}

Fig. 1.

Application of exo-NO sources resulted in reduced ROS production, accumulation of superoxide anion in Daewon (A) and Pungsannamul (B) cultivars after $3 \mathrm{~h}$ (lower case) and 6 h (upper case) of flooding stress. Abbreviation Cont. for control plants without any flood, CF for control with flood, SNP for Sodium nitroprusside application during flooding and CySNO for S-nitroso L-cysteine application during flooding. Data represent the mean of three replicates, while error bars represent standard errors. The differences among the mean values were determined using Duncan's multiple range tests (DMRT) at $P<0.05$. The results were graphically presented using Graph Pad Prism software (version 5.0, San Diego, California USA), while Statistic Analysis System (SAS 9.1) was used for DMRT analysis. 
A
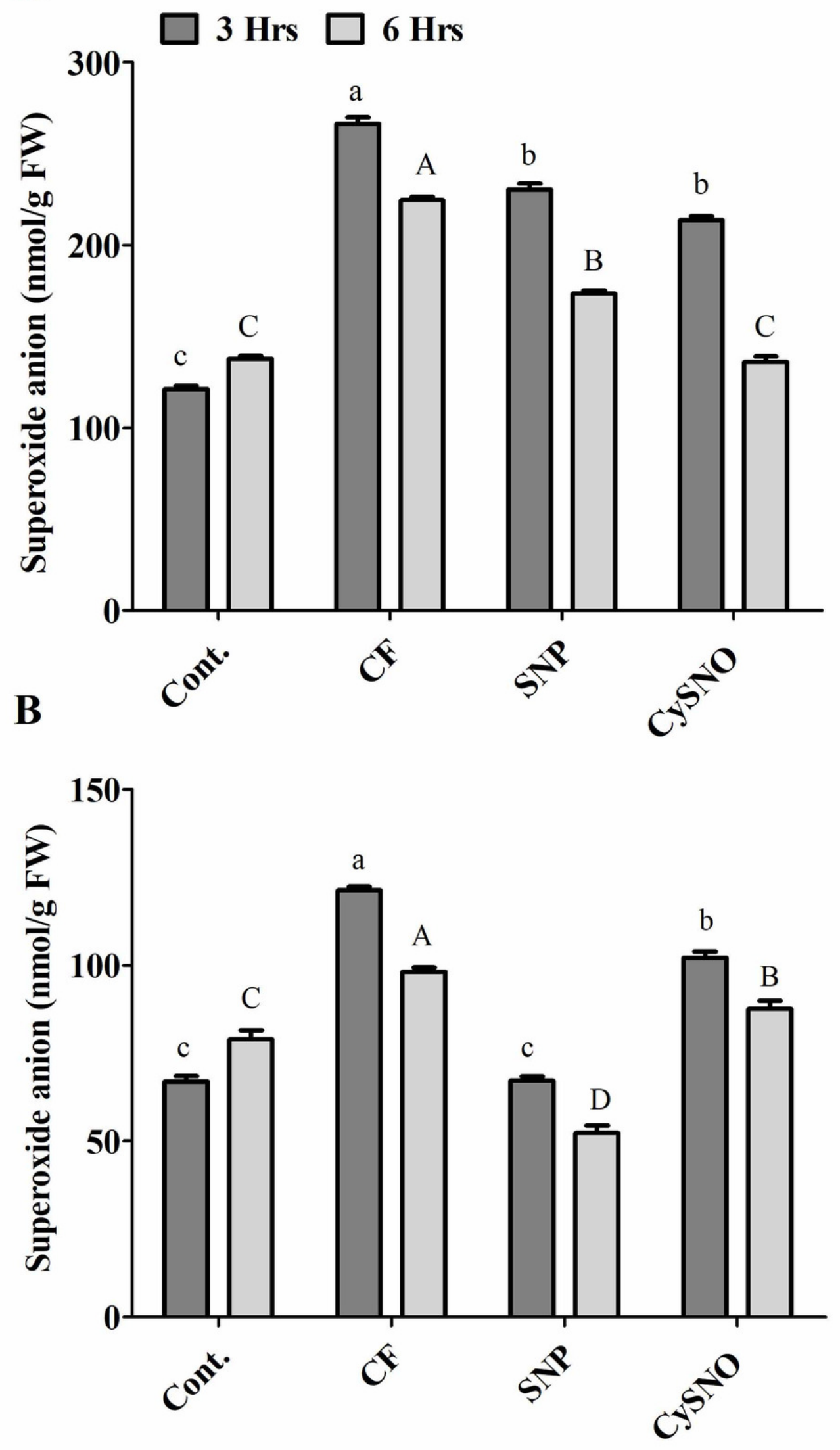


\section{Figure 2}

Fig. 2.

Reduced glutathione in exo-NO sources treated Daewon (A) and Pungsannamul (B) cultivars after $3 \mathrm{~h}$ (lower case) and $6 \mathrm{~h}$ (upper case) of flooding stress. Abbreviation Cont. for control plants without any flood, CF for control with flood, SNP for Sodium nitroprusside application during flooding and CySNO for S-nitroso L-cysteine application during flooding. Data represent the mean of three replicates, while error bars represent standard errors. The differences among the mean values were determined using Duncan's multiple range tests (DMRT) at $P<0.05$. The results were graphically presented using Graph Pad Prism software (version 5.0, San Diego, California USA), while Statistic Analysis System (SAS 9.1) was used for DMRT analysis. 

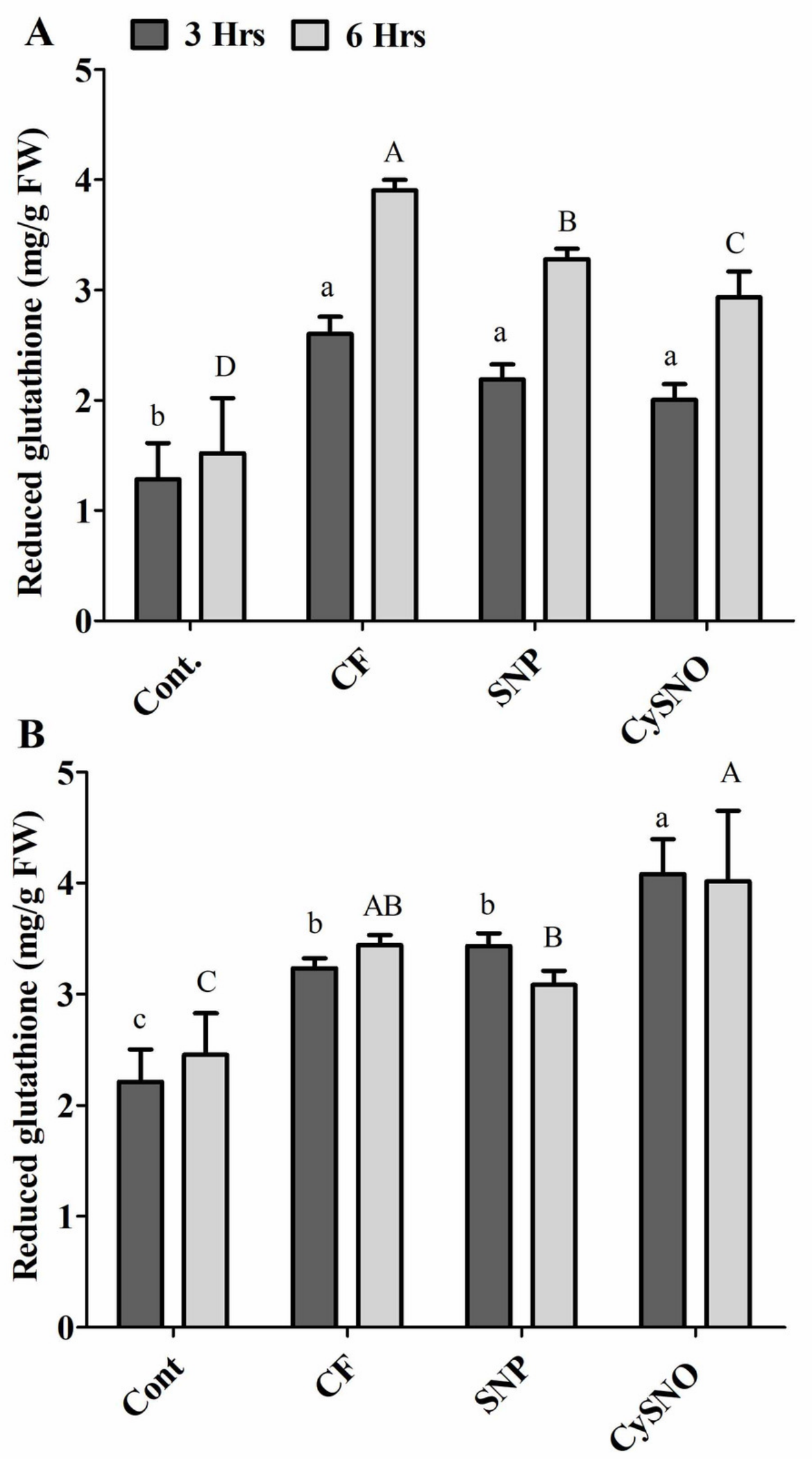


\section{Figure 3}

Fig. 3.

NO regulates cellular ABA levels in Daewon (A) and Pungsannamul (B) cultivars. Total cellular ABA levels after $3 \mathrm{~h}$ (lower case) and $6 \mathrm{~h}$ (upper case) of flooding stress after application of NO sources. Abbreviation Cont. for control plants without any flood, CF for control with flood, SNP for Sodium nitroprusside application during flooding and CySNO for S-nitroso L-cysteine application during flooding. Data represent the mean of three replicates, while error bars represent standard errors. The differences among the mean values were determined using Duncan's multiple range tests (DMRT) at $P<0.05$. The results were graphically presented using Graph Pad Prism software (version 5.0, San Diego, California USA), while Statistic Analysis System (SAS 9.1) was used for DMRT analysis. 

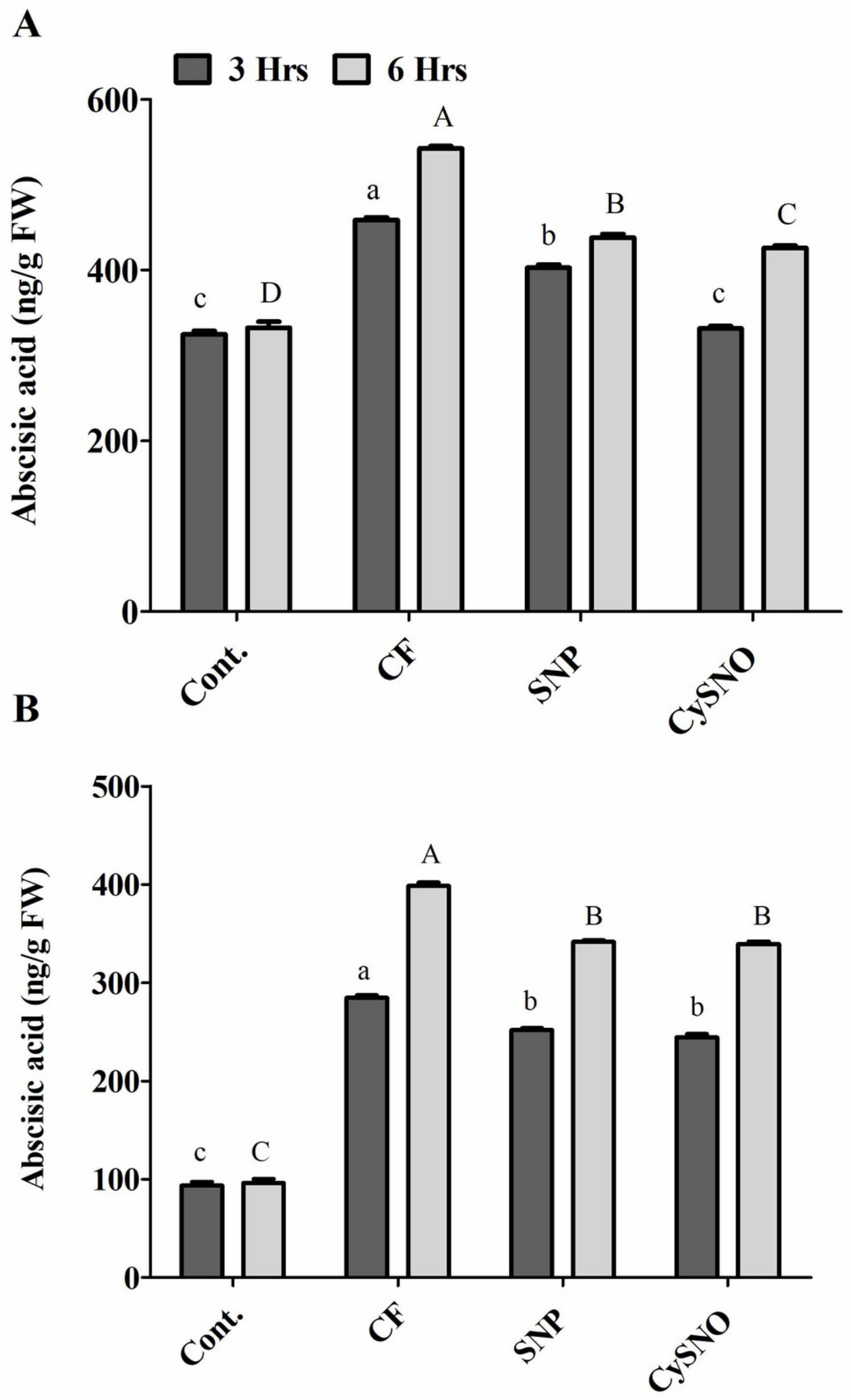


\section{Figure 4}

Fig. 4.

Cellular SNO levels of exo-NO sources treated Daewon (A) and Pungsannamul (B) cultivars after $3 \mathrm{~h}$ (lower case) and $6 \mathrm{~h}$ (upper case) of flooding stress. Abbreviation Cont. for control plants without any flood, CF for control with flood, SNP for Sodium nitroprusside application during flooding and CySNO for S-nitroso L-cysteine application during flooding. Data represent the mean of three replicates, while error bars represent standard errors. The differences among the mean values were determined using Duncan's multiple range tests (DMRT) at $P<0.05$. The results were graphically presented using Graph Pad Prism software (version 5.0, San Diego, California USA), while Statistic Analysis System (SAS 9.1) was used for DMRT analysis. 

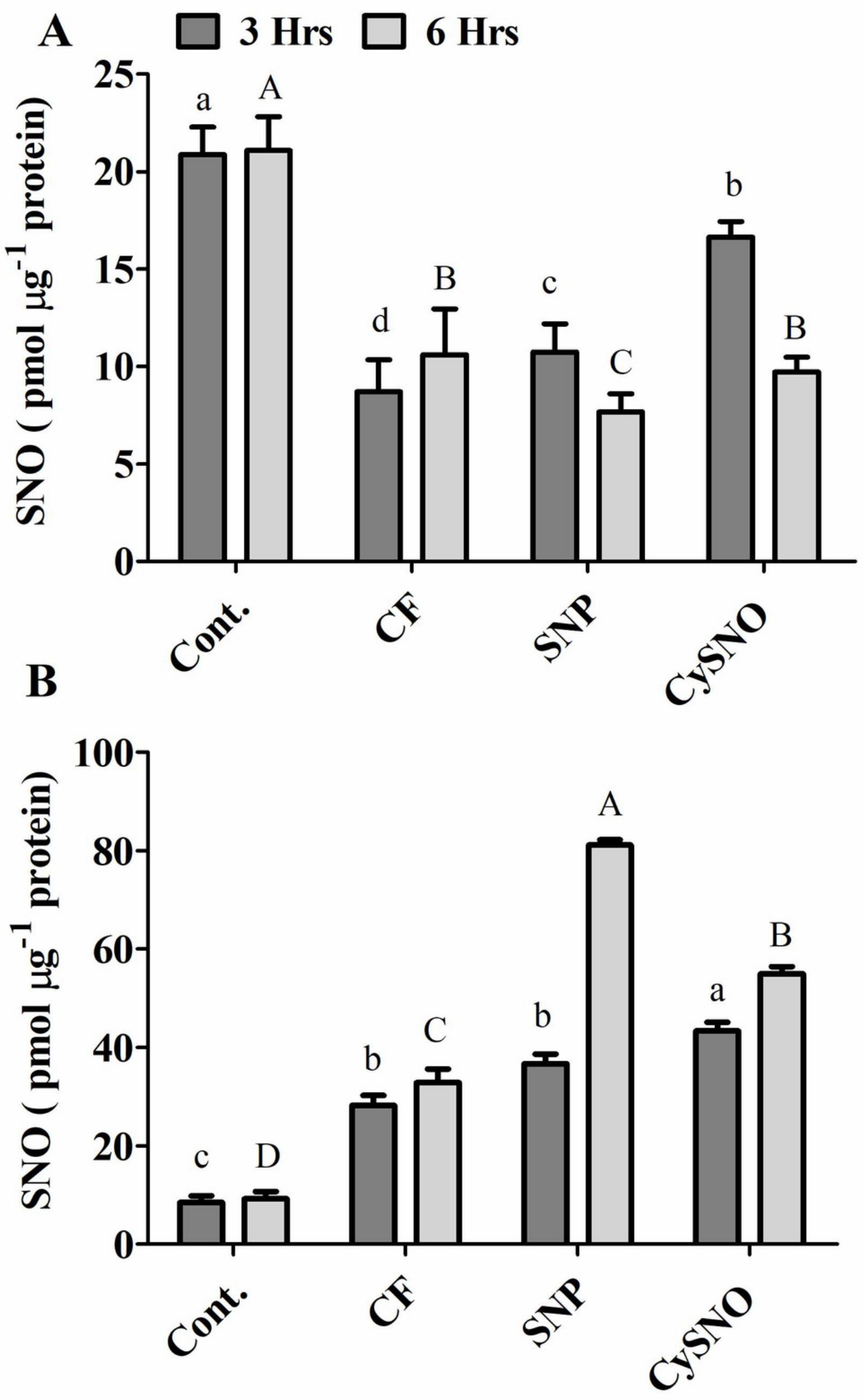


\section{Figure 5}

Fig. 5.

Transcript accumulation of genes involved in nitrogen metabolism. Expression level of GSNOR, NOX1 and NR in exo-NO sources treated Daewon (A, C and E) and Pungsannamul (B, $\mathrm{D}$ and $\mathrm{E}$ ) cultivars after $3 \mathrm{~h}$ (lower case) and $6 \mathrm{~h}$ (upper case) of flooding stress. The values were calculated relative to those of Actin gene and are the means of three replicates, while error bars represent standard errors. The differences among the mean values were determined using Duncan's multiple range tests (DMRT) at $P<0.05$. The results were graphically presented using Graph Pad Prism software (version 5.0, San Diego, California USA), while Statistic Analysis System (SAS 9.1) was used for DMRT analysis. 

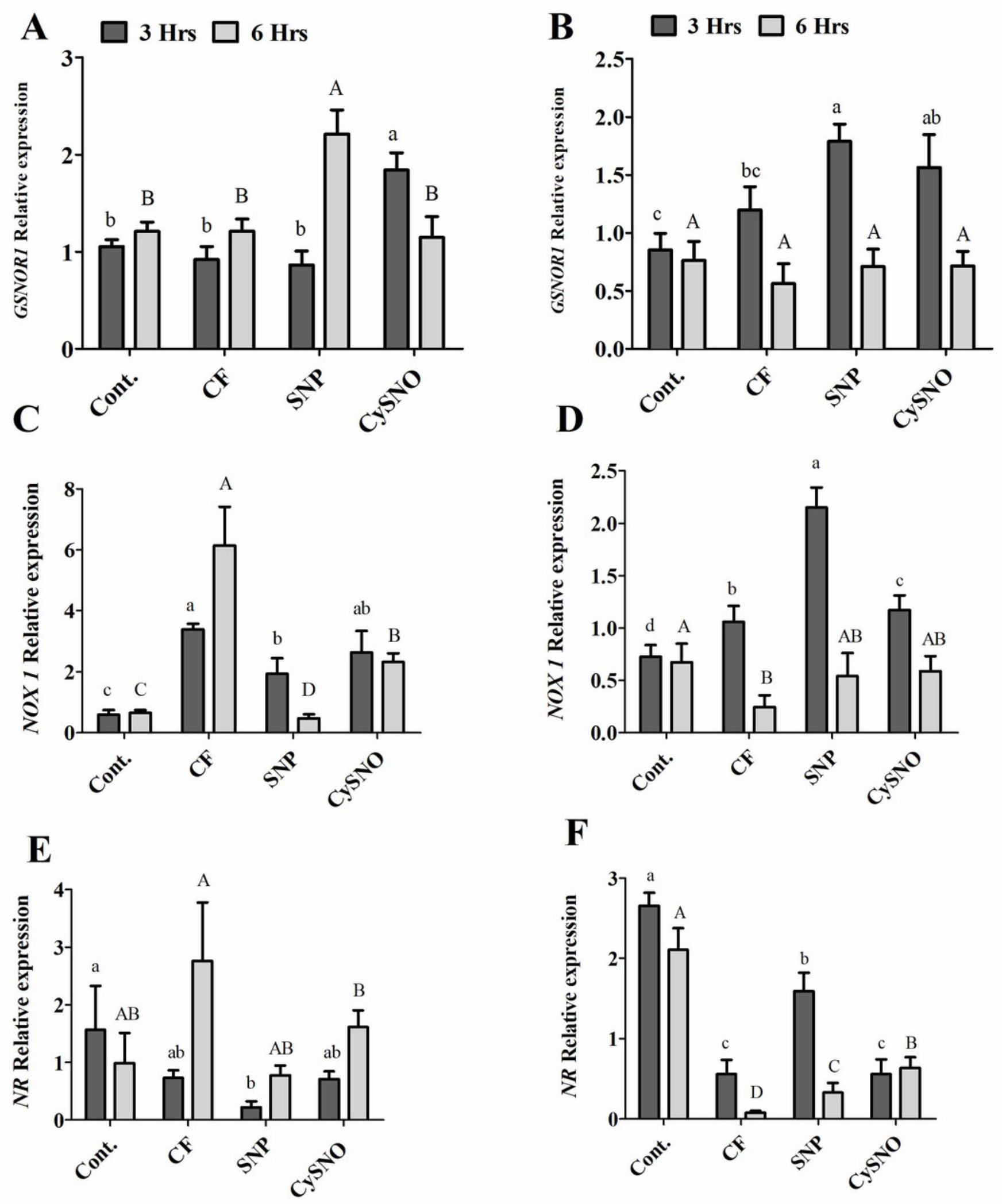


\section{Figure 6}

Fig. 6.

Relative expression of ABA synthesis genes. ABAR and TOC1 in exo-NO sources treated Daewon ( $\mathrm{A}$ and $\mathrm{B}$ ) and Pungsannamul ( $\mathrm{C}$ and $\mathrm{D})$ cultivars after $3 \mathrm{~h}$ (lower case) and $6 \mathrm{~h}$ (upper case) of flooding stress. Abbreviation Cont. for control plants without any flood, CF for control with flood, SNP for Sodium nitroprusside application during flooding, and CySNO for Snitroso L-cysteine application during flooding. The values were calculated relative to those of Actin gene and are the means of three replicates, while error bars represent standard errors. The differences among the mean values were determined using Duncan's multiple range tests (DMRT) at $P<0.05$. The results were graphically presented using Graph Pad Prism software (version 5.0, San Diego, California USA), while Statistic Analysis System (SAS 9.1) was used for DMRT analysis. 

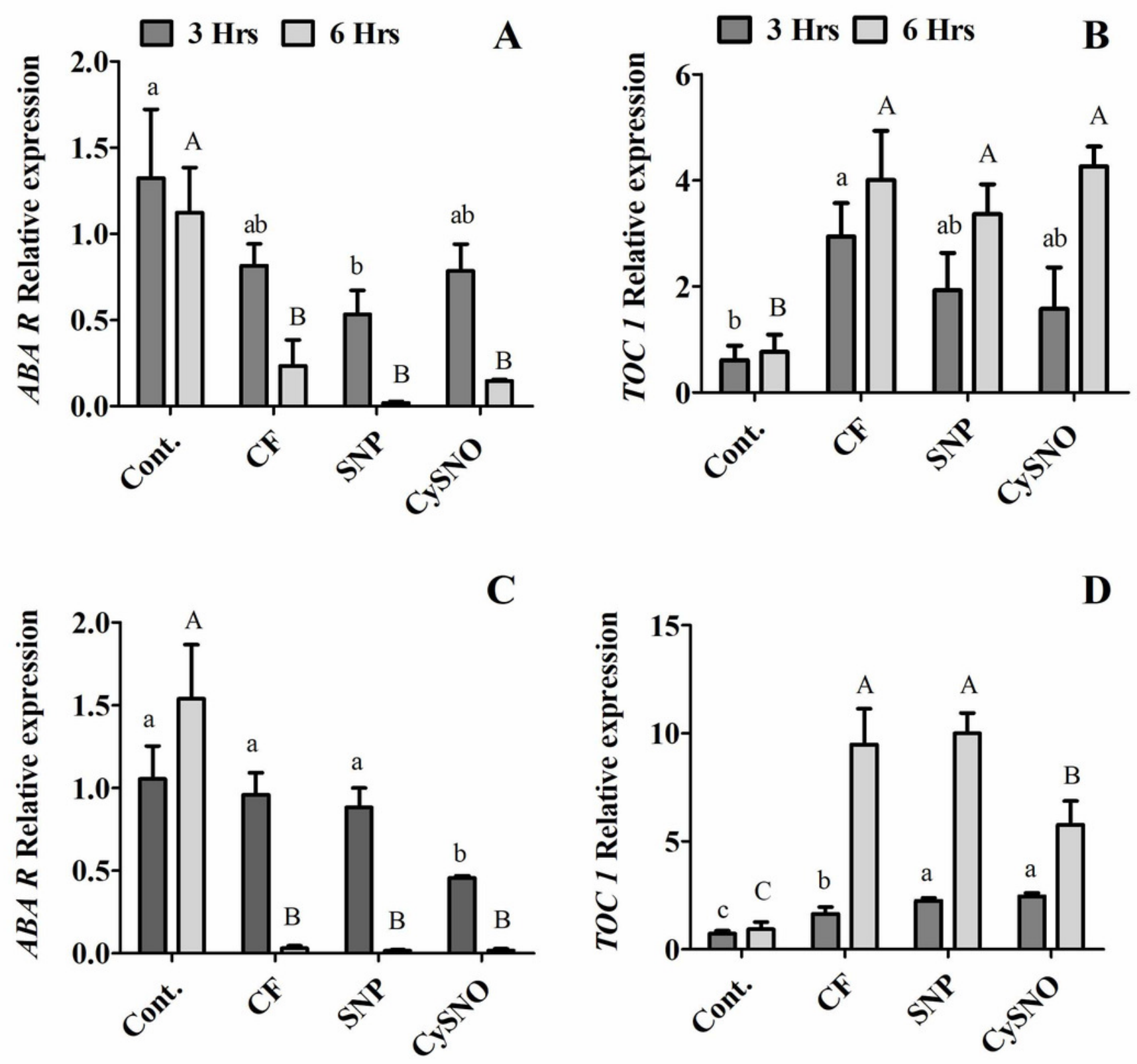


\section{Table $\mathbf{1}$ (on next page)}

List of primers used for NO and ABA related genes through RT-PCR 
1 Table 1. List of primers used for NO and ABA related genes through RT-PCR

\begin{tabular}{|c|c|c|c|}
\hline Gene name & Locus ID & Forward primer $\left(5^{\prime}-3^{\prime}\right)$ & Reverse primer $\left(5^{\prime}-3^{\prime}\right)$ \\
\hline TOC1-1 & $\begin{array}{l}\text { NM_00124827 } \\
3\end{array}$ & TGGCAGCTTGGACTTGTAGA & ATTCACCCCTTGTTGAGCAC \\
\hline GmGSNOR & LOC100499743 & TTGGAATGCTGCCACAAGGG & CCAGACACGTCCACTCACCA \\
\hline$G m N R$ & LOC100813471 & AACCGTCAATACGGCACCCA & TCGTCGTCGCTGGATGAGTC \\
\hline$G m N O X 1$ & LOC732612 & CAGAGCGCGGCTTTCACTTT & CACGTCATCGCTGTTGCTGT \\
\hline$A B A R$ & LOC100787735 & ATCAGGGCAATCAGATGGG & GAGGCGAAGACATTGAGATAGG \\
\hline GmActin & LOC100797704 & $\begin{array}{l}\text { GAGCTATGAATTGCCTGATG } \\
\text { G }\end{array}$ & CGTTTCATGAATTCCAGTAGC \\
\hline
\end{tabular}

2 